\title{
Characterisation of Silver Deposited Coir Fibers by Magnetron Sputtering
}

\author{
Melvi Chandy ${ }^{1}$, U.S. Sarma ${ }^{2}$, M.S. Latha ${ }^{3}$ and K. Shreekrishna Kumar ${ }^{1 *}$
}

\begin{abstract}
Silver thin films are extensively used due to their superior optical, electrical and antimicrobial properties. Recent development in the incorporation silver thin films on natural fibers makes it possible to utilize its excellent physical and chemical properties in the field of textiles. Present study focuses on the surface functionalization of natural coir fiber with silver thin film by magnetron sputtering. This will help to widen the use of natural coir fibers. The surface morphology of the coated coir fibers are investigated by employing a scanning electron microscope. The results show that the surface functionalization of silver-coated coir fibers are highly versatile, and it possess excellent protection against ultraviolet radiation, exhibit excellent hydrophobicity (contact angle $=105.2^{\circ}$ ) and good antibacterial effects. This study demonstrates that treatment, which uses silver thin films by magnetron sputtering, is a promising method for achieving multifunctional coir fabrics.
\end{abstract}

Keywords: Silver thin film/magnetron sputtering/hydrophobicity

${ }^{1}$ School of Technology and Applied Sciences, Mahatma Gandhi University, Malloossery P.O, Kottayam District, Kerala-686 041, India. E-mail: melvichandy@gmail.com

${ }^{2}$ Central Coir Research Institute, Kalavoor Post Office, Alapuzha District, Kerala-688522, India.

${ }^{3}$ S.N. College, Neduvaramcode P. O., Alappuzha District, Kerala-689 508, India.

* To whom correspondence should be addressed. E-mail: kshreekk@gmail.com 


\section{Introduction}

Natural fibres are environmentally friendly materials, with many advantages like ecofriendliness, biodegradability, user friendly etc. Even though they have some markable advantages, inherent drawbacks of the natural fibres are high hydrophilic nature Bledski \& Gassan (1999), low resistance to microbial attack, the tendency to form aggregates during processing and poor surface adhesion for association with a polymer matrix Cho et.al (2002). Various physical and chemical methods have been employed to improve the properties of natural fibers. The chemical method involves dewaxing, delignification, bleaching, acetylation, mercerization, salinization and chemical grafting Mohanty et.al (2001) and physical methods involves plasma treatment, corona treatment, thin film coating and irradiation Seong and Hae (2010).

The coir (Cocos nucifera) is an important lignocellulosic hard and stiff fibre obtained from coconut husk, by the process of retting or mechanical combing. Because of its hardwearing quality, durability and other advantages, it is used for making a wide variety of floor furnishing materials, yarn, rope etc Silver et. al (2001). However, these traditional coir products consume only a small percentage of the total world production of coconut husk and these products are facing stiff completion with the synthetic fiber alternatives. Hence, research and development efforts have been underway to find some diversified application areas for coir fibres including utilization of coir fibres as reinforcement in polymer composites Moteiro et. al (2008), desiccant materials Ratanakaran et. al (2010) geotextiles, and sound absorbents. Wassilief (1996).

In recent years, natural fiber industries have been focussing on improving the functional properties of fibers such as UV protection, fire retardency, and antibacterial properties. Tremendous effort has been made to apply silver thin films on fibers, including electroless plating, electroplating, and vacuum deposition. However, such conventional techniques generally use wetchemical processing and produce much waste water. On the other hand, as eco friendly and dry technology, sputtering is an attractive alternative by adding new functionalities such as hydrophobicity, UV protection and antibacterial properties, making it a promising technique for future applications. The ability to deposit a wellcontrolled silver coating on textiles would extent the applications of coir fibers, based on changes to both the physical and chemical properties of textiles. Not much study has been reported on the surface functionalisation of coir fibers.

This investigation is directed towards coating of coir fibers with silver thin films by magnetron sputtering technique. Their morphological characterisation is studied by using SEM. Moreover the coated coir fibers are studied to characterise the functional properties such as hydrophobicity and antibacterial activity. The thermal stability of the coated fibers are also studied.

\section{Experimental}

Silver target with high purity (purity: 99.99\%) is used to deposit silver thin films onto coir fiber by using a magnetron sputtering system. The dimensions of the silver target are $50 \mathrm{~mm}$ in diameter and $5 \mathrm{~mm}$ in thickness. In the present study acetone is used for removing the fats and oils on the coir fiber substrates. Prior to deposition, the coir fiber samples are first immersed into an acetone solution for $2 \mathrm{~min}$, and then washed thrice with deionised water. Following that, the coir samples are dried at a temperature of $80^{\circ} \mathrm{C}$ for 24 hours.

The pressure before evaporation is kept at $2 * 10^{-6}$ Torr and then it is increased to about $7 * 10^{-6} \quad$ Torr when argon is introduced into the vacuum chamber as the bombardment gas. The deposition rate is $1 \AA \hat{A} / \mathrm{sec}$ for all coating. The thickness of the coating was monitored by using a quartz crystal monitor. The sputtering current and voltage are maintained at $0.15 \mathrm{~A}$ and $115 \mathrm{~V}$ respectively. Since the size and shape of the coir fibers may vary from fiber to fiber, we had taken a set of 20 samples to produce reliable results. The deposition time is $10 \mathrm{~min}$ and $20 \mathrm{~min}$ on the samples. 
The surface morphology and chemical composition analysis of the silver coated coir fibers are performed by a scanning electron microscope (SEM). The thermal stability of the uncoated (UC) and silver coated (SC) are evaluated by means of a thermo gravimetric analyser. Water contact angle (WCA) of the samples is measured at ambient temperature using a SEO Phoenix optical contact angle system. A volume of $5 \mu 1$ water is applied in this test. The hydrophobicity of the silver coated coir fabrics are further confirmed by water drops test, floatation and swelling tests.

Antibacterial tests on UC and SC coir fibers are carried out following the Standard 'SNV 195920-1992'. The antibacterial activity of the samples is assessed through a diffusion test in Agar Aldrich). In this method, an E. Coli colony is positioned in a petri dish filled with agar gel. UC and SC fibres are placed over the colony and the whole dish is incubated in oven at $37^{\circ} \mathrm{C}$ for $24 \mathrm{~h}$. After this period of time, the dish is removed from the oven and the area covered by the bacterial colony with respect to the samples is evaluated. If a growth inhibition zone is observed close to the sample (characteristic zone size $\geq 1 \mathrm{~mm}$ ), antibacterial property is indicated as 'good'. If the sample is totally rehabitated by the bacteria, the antibacterial property is indicated as 'not sufficient'.

\section{Results and discussion}

The surface morphology of the coated and uncoated coir fibers is shown in the Fig. 1 The SEM study confirms that silver particles are grafted on to the fiber suraface. The surface of uncoated coir fiber shows the presence of micro pores. Metal coated fiber, on the other hand is smooth and without any pores indicating the formation of metal layer on the surface. After sputtering for 10min, a thin layer of silver is obtained on the fiber surface. With an increase in sputtering time homogenous silver depositions are observed on the coir fibers.

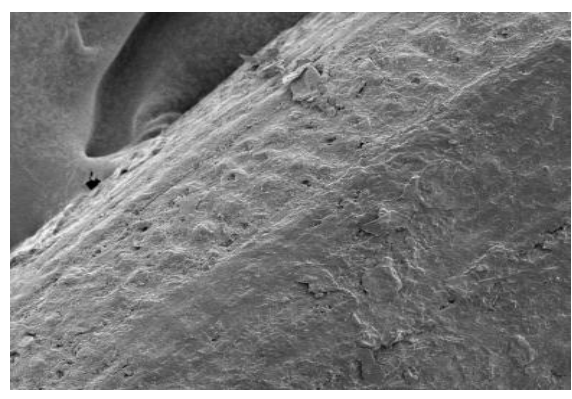

(a) untreated

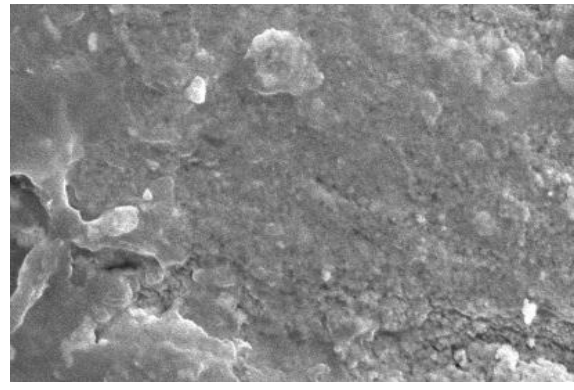

(b) silver coated (10min)

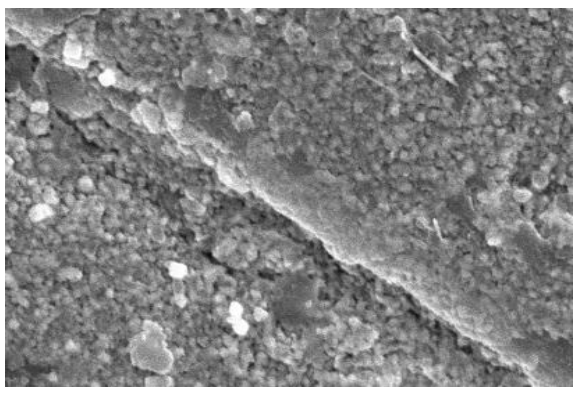

(c) silver coated (20min)

Figure 1.

The hydrophobicity of the silver coated and uncoated coir fibers is examined by WCA measurement. Fig. 2 shows the microscopic view of the contact angle. Generally coir fibers are highly hydrophilic due to the presence of abundant hydroxyl groups on the surface. When metal particles are coated on the surface of the fabric, the fabric becomes hydrophobic. The easy rolling of the water droplet on the fabric surface is the primary evidence for that. The hydrophobisation occurs due to the layer of metal coated on the surface of the coir fiber. The WCA on the surface of the coir fabric coated with silver for ten selected areas is measured as 105.2. $2^{\circ}+/-$ $2.5^{\circ} \mathrm{C}$ for a $5 \mu 1$ water droplet on the silver coated 
fabric. The WCA measurement of silver coated fabric (20 minutes) is $106.3^{\circ} \mathrm{C}$. All the samples showed almost same WCA measurements. After 5 washes the metal coated coir fabrics shows $25 \%$ decrease in the WCA as compared to the uncoated one. The reason for this decrease in WCA of coated fabric is due to the slow removal of metal particles from the surface of the coir fabric during washing.
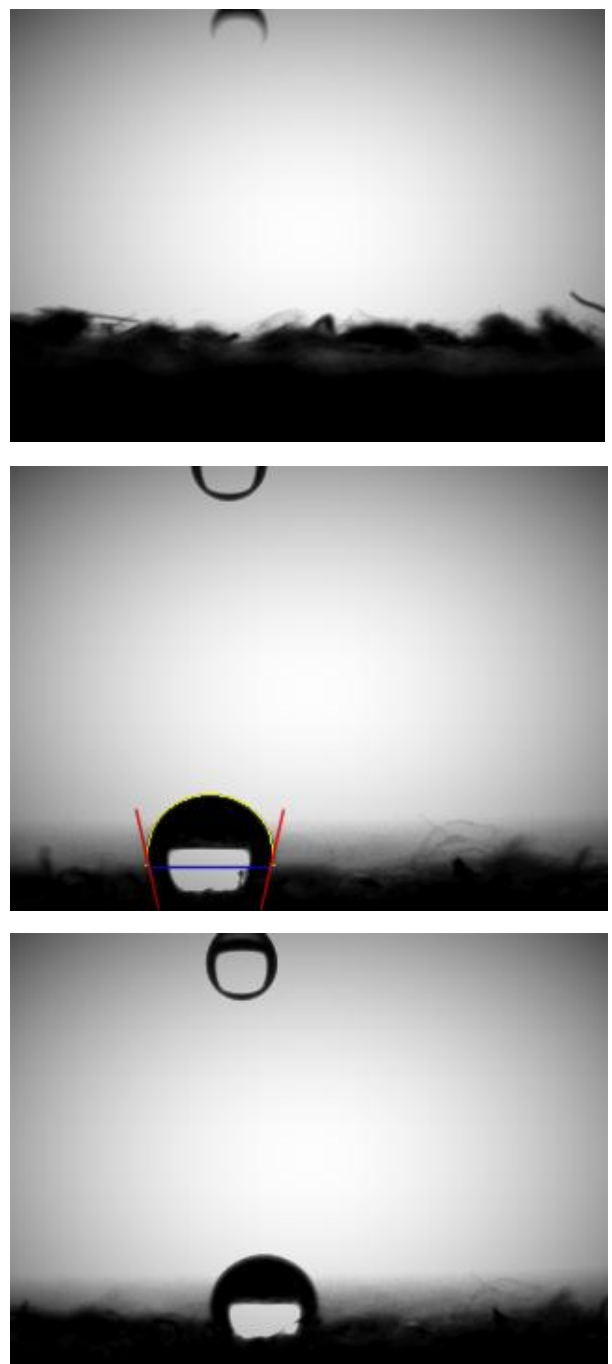

Figure 2. Microscopic view of water contact angle

The water repellent property is further confirmed by water drops test and floatation tests. In water drops tests, the drops of controlled size are placed at a constant rate upon the fabric surface and duration of time required for them to penetrate the fabrics are measured. The results are shown in Table 1, in which the absorption time is recorded for different metal coated coir fabrics. From the results it is clear that the water repellency of the coir fabric is increased considerably with the metal coating. In the case of uncoated coir fabric the water droplet disappears immediately within seconds, with water spreading over large areas. In the case of coated fabric the droplet remained spherical even after 30min with no spreading, indicating that all the modified fabrics are water repellent. From the floatation tests (Fig 3) it is found that the coated fabric floated on the surface of water for more than 100 minutes, whereas the uncoated coir fabrics gradually sink to the bottom, when they are placed on the water surface. Fig 4 shows the variation of percentage water absorption coated and uncoated coir fabric with time. More absorption of water is obtained in untreated coir fabric and lesser absorption in metal coated coir fabrics. The samples with 20minutes sputtering time showed lesser absorption of water at ambient temperature than the respective untreated sample.
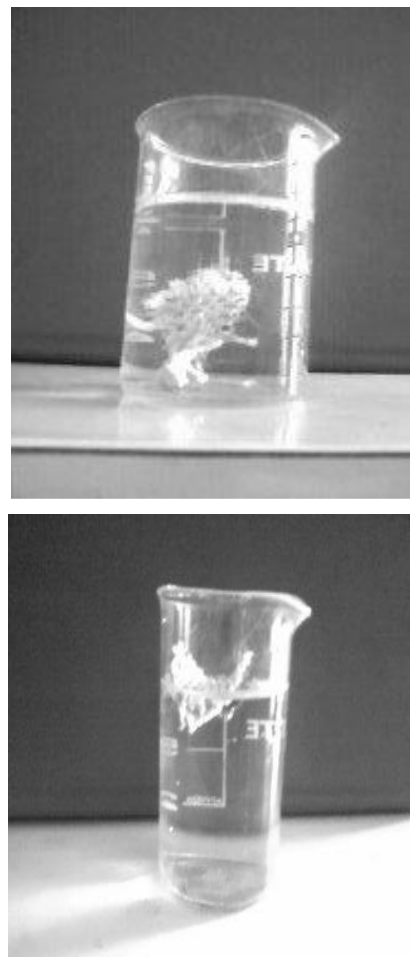

Figure 3. Floatation tests for a) uncoated and b) silver coated coir fabric 


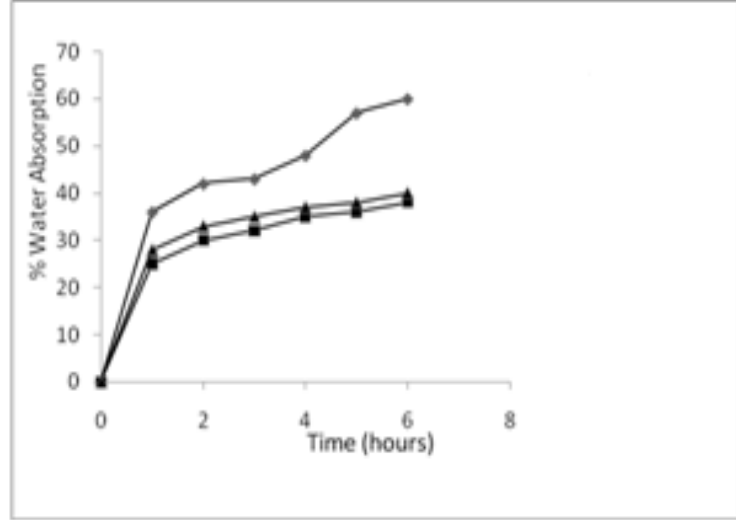

Figure 4. Water absorption versus time - untreated coir fiber $\Delta$ Silver coated (10min sputter coated - Silver coated (20 min sputter coated

Table 1. Absorption time of untreated and silver coated coir fibers

\begin{tabular}{l|c}
\hline Samples & Absorption time \\
\hline Untreated & $3 \mathrm{~s}$ \\
Ag coated sample for 10min & $>100 \mathrm{~min}$ \\
Ag coated sample for 20min & $>100 \mathrm{~min}$ \\
\hline
\end{tabular}

The thermal stability of the uncoated and coated fibers is found out by using TGA. The TGA of all the coated and uncoated samples are shown in Fig $5 \mathrm{a} \& 5 \mathrm{~b}$. From the figure it is evident that the thermal stability increased by metal coating. In the case of untreated coir fabrics there are three stages of degradation. The first one is attributed to the evaporation of water and occurs between room temperature and $150^{\circ} \mathrm{C}$. The second step, which corresponds to the hemicelluloses degradation, starts at about $190^{\circ} \mathrm{C}$; the third step occurs between 290 and $360^{\circ} \mathrm{C}$, corresponding to thermal degradation of cellulose. Lignin presents a broad peak throughout the range, degrading between 280 and $500^{\circ} \mathrm{C}$. The untreated coir fibers are completely oxidised to form char residue at $700^{\circ} \mathrm{C}$ Alvaraz \& Wasquez (2004), Tomzac et. al (2007). Metal coating is found to have a considerable effect on the thermal degradation behaviour of the coir fibers, promoting an increase in the temperature at which the thermal degradation take place These changes may be attributed to the quick distribution of heat on the surface of the coated coir fabric when compared to uncoated one.

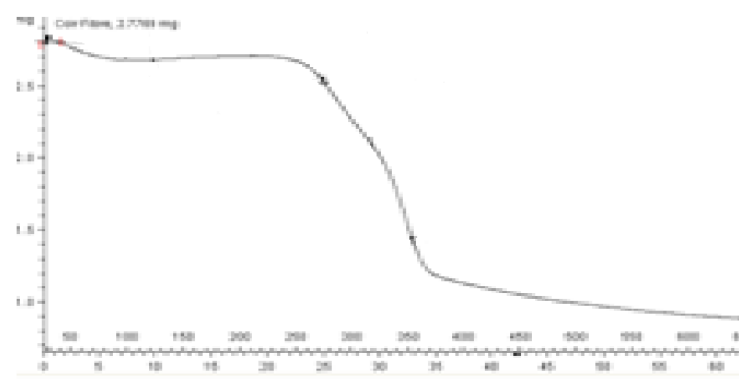

(a)

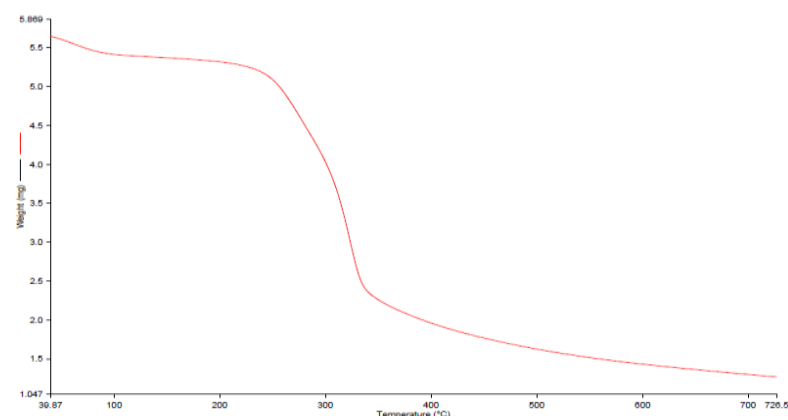

(b)

Figure 5. TGA analysis of a) untreated fiber b) silver coated (10min)

Table 2. Thermogravimetric analysis of coir fibers and silver coated coir fibers

\begin{tabular}{|lllll|}
\hline No. & Sample & $\begin{array}{l}\text { Transition } \\
\text { temperature } \\
\text { range }\left({ }^{\mathbf{0}} \mathbf{C}\right)\end{array}$ & $\begin{array}{l}\text { Temperature } \\
\text { of maximum }\end{array}$ & $\begin{array}{l}\text { Weight } \\
\text { loss } \\
\text { (\%) }\end{array}$ \\
\hline 1 & Untreated & $30-150$ & 53 & 5 \\
& & $150-297$ & 286 & 26 \\
& & $297-500$ & 334 & 45 \\
2 & & & & \\
& $\begin{array}{l}\text { Silver } \\
\text { coated }\end{array}$ & $30-170$ & 55 & 5 \\
& & $170-320$ & 301 & 26 \\
& & $320-500$ & 360 & 49 \\
\hline
\end{tabular}




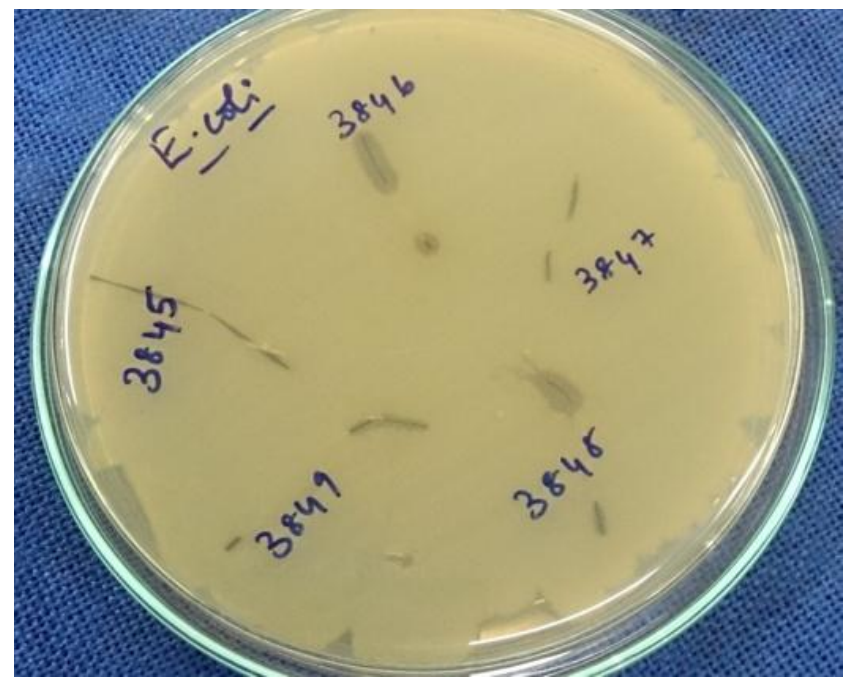

Figure 7. Antibacterial Activity Test

Table 3. Characteristic antibacterial zone for coated and uncoated coir fiber

\begin{tabular}{|cccccc|}
\hline No. & Sample & $\begin{array}{c}\text { Sputtering } \\
\text { Time (min) }\end{array}$ & Bacteria & $\begin{array}{c}\text { Inhibition } \\
\text { Zone }\end{array}$ & $\begin{array}{c}\text { Level of } \\
\text { antibacterial } \\
\text { capacity. Pollini } \\
\text { et. al (2009) }\end{array}$ \\
\hline 1 & $\begin{array}{l}\text { Untreated } \\
(3845)\end{array}$ & E. Coli & ----- & Not sufficient \\
2 & $\begin{array}{l}\text { Silver Coated } \\
(3847 \text { \& 3849) }\end{array}$ & 10 & E. Coli & $<1 \mathrm{~mm}$ & Fairly good \\
3 & $\begin{array}{l}\text { Silver Coated } \\
(3846 \& 3848)\end{array}$ & 20 & E. Coli & $>1 \mathrm{~mm}$ & Good \\
\hline
\end{tabular}

In literature it is reported that, either polyester or cotton fibers coated by silver exhibit antibacterial capability against E. coli. In this study antibacterial tests are performed on an uncoated and silver coated coir fiber. The effect of silver compared with the control samples is determined by measuring the size of the area of inhibition growth close to each sample. As clearly shown in Fig. 3, the E. coli colony seeded in the petri dish filled with agar grows on the untreated coir sample after incubation in oven at $37^{\circ} \mathrm{C}$ for $24 \mathrm{~h}$ : untreated coir fiber does not display any antibacterial activity. The characteristic antibacterial zone of uncoated and coated coir fibers are given in Table 3. Silver in its metallic state is inert, but it reacts with moisture on the skin and fluid on a wound, and become ionized. The ionized silver is highly reactive as it binds to tissue proteins and brings structural changes to the bacterial cell wall and nuclear membrane leading to cell distortion and death. Jiang et. al (2010). It can be observed a clearly defined bacterial free zone around each coated sample which confirms the growth inhibition effect induced by silver ions. 


\section{Conclusion}

Silver thin films on coir fibers are prepared by magnetron sputtering technique. SEM anlysis shows a uniform layer of silver over the coir fiber surface. The results obtained from water contact angle confirms that the hydrophobicity of the silver coated coir fabric is higher than that of the uncoated fabric. Silver coated coir fabrics show excellent antibactrial activity against E. Coli. as confirmed by the antimicrobial tests. Such silver coated coir fabric could therefore be used in water repellent coating and antibacterial applications. The investigation described suggests that the silver coated coir fabrics will be promising multifunctional material for military and medical application.

\section{References}

Alvaraz V.A, Vazquez. 2004. Thermal degradation of cellulose derivatives/starch blends ans sisal fiber biocomposites, Polymer degradation and stability, 84; 1321.

Bledski AK, Gassan J. Composites reinforced with cellulose based fibers. 1999. Progress in Polym. Sci.; 24: 221-274.

Cho A, Lee SG, Park WH, Han SO. 2002. Ecofriendly biocomposite materials using biofibrils. Polym. Sci. Technol. I; 13; 460476.

Mohanty AK, Misra M, Drsal LT. 2001. Surface modification of natural fibers and performance of the resulting composites; an overview, Comp Interfaces, 8: 313-43.

Moteiro SN, Terrones LAH, Almeida JRM. 2008. Mechanical performance of coir fiber/polyester composites, Polymer Testing, 591-595.

M. Pollini, M. Russo A. Licciulli, A. Sannino, A. Maffezzoli. 2009. Characterization of antibacterial silver coated yarns, Journal of Material Science, 20, 2361-2366.
Ratanakorn Rawangkula, Joseph Khedaria, Jongjit Hirunlabhb, Belkacem Zeghmatic. 2010. Characteristics and performance analysis of a natural desiccant prepared from coconut coir, Science Asia, 36; 216222.

Seong OH, Hae YC. 2010. Morphology and surface properties of natural fibers treated with electron beam. Microscopy: Science Tachnology, Applications and education, 1880-1888

Silva GC, Souza DA, Machado JC, Hourston DJ. 2001. Mechanical and thermal charecerization of Brazilia coir fibers, Journal of Applied Polymer science, 76, 1197-1206

S.X. Jiang, W.F. Qin, R.H. Guo, L. Zhang. 2010. Surface functionalisation of nanostructured silver coated polyester fabric by magnetron sputtering, Surface Coating and Technology, 204, 3662-3667.

Tomzac, F., Satyanarayana, K.G., Sydenstricker, T.H.D. 2007. Studies on lignocellulosic fibers of Brazil: Part II- morphology and properties of Brazilian coconut fibers, Composites: Part A, Applied Science and Manufacturing, 38, 1710-1721.

Wassilief C.1996. Sound absorption of wood based materilas, Applied acoustics, 48; 339-356. 